\title{
Fitossociologia de uma Floresta Ombrófila Densa na Amazônia Setentrional, Roraima, Brasil
}

\author{
Tiago Monteiro CONDÉ 1 , Helio TONINI ${ }^{2}$ \\ RESUMO \\ O presente estudo teve como objetivo caracterizar a composição florística e fitossociológica de uma floresta nativa no município \\ de Caracaraí, Roraima, Brasil. Foram inventariadas todas as árvores com DAP $\geq 10 \mathrm{~cm}$ em 9 parcelas permanentes de $100 \mathrm{x}$ \\ $100 \mathrm{~m}$ (1 ha cada). Foram observados 4.724 indivíduos $\left(525\right.$ ind.ha $\left.^{-1}\right)$, distribuídos em 42 famílias botânicas, 111 gêneros e \\ 165 espécies. As famílias com maior número de indivíduos foram Fabaceae (1.883), Lecythidaceae (609) e Sapotaceae (434), \\ perfazendo $52 \%$ do total de indivíduos amostrados. O grupo composto por espécies pioneiras apresentou maior número de \\ indivíduos (219 ind.ha $\left.{ }^{-1}\right)$, seguido das secundárias (193 ind.ha ${ }^{-1}$ ) e climácicas (113 ind.ha $\left.{ }^{-1}\right)$. No entanto, as secundárias obtiveram \\ maior número de espécies (95), em detrimento de climácicas (44) e pioneiras (26). O índice de diversidade de Shannon $\left(\mathrm{H}^{\prime}=\right.$ \\ $3,27)$ e o valor de equabilidade de Pielou $(J=0,64)$ foram inferiores aos obtidos em outros inventários florísticos na Amazônia \\ Legal, contribuindo para isso o tamanho populacional de Pentaclethra macroloba. As espécies Pentaclethra macroloba $(52,1)$, \\ Eschweilera bracteosa $(23,7)$ e Pouteria caimito $(8,1)$ apresentaram os maiores valores de importância, perfazendo $28 \%$ do VI \\ total. A maior parte dos indivíduos amostrados $\left(71,3 \%=374\right.$ ind.ha $\left.{ }^{-1}\right)$ foram registrados no estrato médio $(12,4 \mathrm{~m} \leq$ altura \\ $<26,5 \mathrm{~m}$ ) da floresta. A comunidade florestal pode ser considerada bem estruturada, madura e diversa, portanto em bom \\ estado de conservação.
}

PALAVRAS-CHAVE: diversidade, espécies amazônicas, Fabaceae, Pentaclethra macroloba.

\section{Phytosociology of a dense ombrophilous forest in the northern Amazon, Roraima, Brazil}

\section{ABSTRACT}

This study was carried out to characterize species composition and phytosociology of a native forest located at Caracaraí, Roraima, Brazil. All trees with breast diameter (DBH) above $10 \mathrm{~cm}$ in nine 1-ha-permanent plots $(100 \mathrm{x} 100 \mathrm{~m}$ each) were inventoried. We observed 4,724 individuals (525 trees per hectare) distributed in 42 families, 111 genera and 165 species. The families with greater number of individuals were Fabaceae (1883), Lecythidaceae (609) and Sapotaceae (434), comprising 52\% of the total. The higher densities of individuals were observed in the pioneer $\left(219\right.$ trees ha $\left.{ }^{-1}\right)$, followed by secondary (193 trees $\mathrm{ha}^{-1}$ ) and climax species $\left(113\right.$ trees ha $\left.{ }^{-1}\right)$. However, species of secondary group had the highest species richness (95), followed by the climax (44) and the pioneer (26). The Shannon diversity index $\left(\mathrm{H}^{\prime}=3.27\right)$ and the value of Pielou equability $(\mathrm{J}=0.64)$ were lower than those obtained in other floristic inventories in the Amazon, because of the high occurrence of Pentaclethra macroloba. The importance values (VI) were higher for Pentaclethra macroloba (52.1), Eschweilera bracteosa (23.7) and Pouteria caimito (8.1). The importance values of these three species alone accounted for $28 \%$ of the total VI across species. Most of the individuals $\left(71.3 \%=374\right.$ trees ha $\left.^{-1}\right)$ were recorded in the middle stratum $(12.4 \mathrm{~m} \leq$ height $<26.5 \mathrm{~m})$ of forest. The forest community can be considered well-structured, mature and diverse, and so it is in good state of conservation.

KEYWORDS: Amazon species, diversity, Fabaceae, Pentaclethra macroloba.

\footnotetext{
${ }^{1}$ Universidade Estadual de Roraima (UERR) - Coordenação de Ciências Exatas e Agrárias. Av. Senador Helio Campos, s/n, CEP 69373-000, Rorainópolis/RR. Email: tiagonafloresta@gmail.com

2 Embrapa Agrossilvipastoril. Rodovia MT 222, km 2,5, CEP:78550-970, Sinop/MT. Email: helio.tonini@embrapa.br
} 


\section{INTRODUÇÃO}

As comunidades arbóreas tropicais são de especial interesse em estudos de fitossociologia, devido à ampla variedade de padróes e processos relacionados às suas diversidades. $\mathrm{A}$ floresta Amazônica ainda é pouco conhecida floristicamente: as grandes lacunas de conhecimento em termos geográficos e o pequeno número de coleçôes disponíveis em herbários impedem um mapeamento acurado da distribuição das plantas e da biodiversidade e a identificação de regiôes de endemismo, dificultando o planejamento adequado para a conservaçáo e o uso sustentável da biota regional (Hopkins 2007).

A regiáo norte da Amazônia Brasileira, que se estende do nordeste do estado do Amazonas, sul do estado de Roraima e a porçáo do estado do Pará, localizada cerca de $300 \mathrm{~km}$ ao norte do Rio Amazonas e incluindo o extremo sul da Guiana, foi considerada por Hopkins (2007) como uma das regiôes de alta biodiversidade esperada e baixo conhecimento botânico.

O estado de Roraima carece de informaçóes confiáveis a respeito de seus biomas, principalmente de suas florestas que atualmente estão sofrendo modificaçóes estruturais, oriundas de desmatamentos, construçóes de vicinais ligadas a assentamentos de reforma agrária e de extração de madeira sem critério. Em trabalho realizado por Barni et al. (2012), foram realizadas constataçôes de perdas de biodiversidade de florestas no sul do estado de Roraima, contribuindo para emissão significativa de gás carbônico à atmosfera, ligadas principalmente a expansão da malha viária amazônica e projetos de assentamento de reforma agrária.

Informaçôes sobre a estrutura e a composição florística obtidas através dos inventários florestais estão entre as principais ferramentas disponíveis para a avaliação do potencial de uma floresta e a definição de estratégias de manejo (Francez et al. 2007). Diversos estudos desenvolvidos na Amazônia têm demonstrado que os ambientes florestais de terra firme, ou seja, as florestas de platô e vertente apresentam alta diversidade, representada por poucos indivíduos de cada espécie e com valores bastante variáveis de diversidade e similaridade (Prance et al. 1976; Lima Filho et al. 2004).

Em termos de manejo florestal sustentado para a produçấo de madeira, as diferenças regionais na fitofisionomia das florestas, na autoecologia das espécies e no contexto socioeconômico em que a atividade é praticada tornam de grande importância à geração de informaçôes em áreas ainda pouco estudadas como o estado de Roraima.

$\mathrm{Na}$ Amazônia são vários os estudos envolvendo diferentes intensidades de exploraçáo florestal, utilizando-se ou não tratamentos silviculturais, com o intuito de detectar alteraçôes ocorridas na composição florística, nas taxas de crescimento, na regeneração, na mortalidade e ingresso (Finegan e Camacho 1999; Carvalho et al. 2004). Segundo Silva et al. (2005), as parcelas permanentes são a fonte mais confiável de detecção das modificaçôes estruturais em ecossistemas florestais.

Estudos dessa natureza fornecem parâmetros confiáveis para subsidiar a classificação de espécies arbóreas em grupos sucessionais (pioneira-secundária-clímax), levando-se em consideração: exigências de luz, ecologia, dinâmica e crescimento das espécies em clareiras naturais e antrópicas e em áreas sem distúrbios. Segundo Santos et al. (2004) e Archanjo et al. (2012), a maioria dessas classificaçôes se baseiam na divisão das espécies florestais entre aquelas de estágios iniciais e tardios da sucessão.

O presente estudo visa caracterizar a composiçāo florística e fitossociológica de uma floresta nativa ainda não manejada em uma área de manejo florestal no município de Caracaraí, Roraima, relacionando os aspectos da diversidade, da estrutura e do estado de conservação da mesma.

\section{MATERIAL E MÉTODOS}

A área experimental está localizada no município de Caracaraí, no estado de Roraima, Brasil. A formação florestal em estudo é caracterizada como Floresta Ombrófila Densa de terra firme e está completamente inserida no Plano de Manejo Florestal Sustentável da empresa Madeireira Vale Verde Ltda.. A área destinada ao manejo florestal perfaz 17.205,4 ha. A topografia da Área de Manejo Florestal (AMF) é de suave a ondulada, com altitude variando de 60 a $120 \mathrm{~m}$ na parte oeste e uma regiáo de serra na parte sudoeste, onde a altitude pode chegar a $330 \mathrm{~m}$. Os solos predominantes da AMF são: Argissolo Vermelho-Amarelo (PVA) e Latossolo VermelhoAmarelo (LVA), conforme descrito em Vale Verde (2012).

O município de Caracaraí é parcialmente dividido pelo Rio Branco e detém a maior área física de Roraima. O clima, segundo a classificação Köppen, é do tipo tropical chuvoso sem estaçáo seca (Af), com os totais anuais de precipitaçáo pluviométrica relativamente elevada, em torno de $1.750 \mathrm{~mm}$ (Programa Calha Norte 2010).

Utilizando o método descrito por Silva et al. (2005), foram instaladas aleatoriamente nove parcelas permanentes de 1 ha cada (100 x 100 m), com uma distância mínima em torno de $50 \mathrm{~m}$ entre cada uma, em ambientes semelhantes de floresta nativa ainda náo manejada, portanto em bom estado de conservação em Caracaraí-RR, Brasil (Datum SAD69, Coordenadas Geográficas: 6056 '0" W e 1'50’30” N). Cada parcela permanente foi subdividida em 100 subparcelas (10 x 10 m cada), iniciando-se pelo canto sudoeste. Nestas subparcelas foram mensuradas e identificadas botanicamente todas as árvores com DAP $\geq 10 \mathrm{~cm}$. Todas as subparcelas foram numeradas e todas as árvores com DAP $\geq 10 \mathrm{~cm}$ foram plaqueteadas e pintadas ao ponto de medição, estabelecido a 1,30 m do solo, conforme Silva et al. (2005). 
A identificação botânica foi realizada mediante inventário florístico realizado por parabotânico do Instituto Nacional de Pesquisas da Amazônia - INPA. Um exemplar de cada espécie foi coletado. As amostras foram submetidas à secagem em estufa $\left(70^{\circ} \mathrm{C}\right)$ por 48 horas em laboratório na Embrapa Roraima. Em seguida, as amostras foram encaminhadas ao Herbário INPA, sendo identificadas comparadamente com as exsicatas disponíveis nesse herbário. Uma exsicata de cada espécie foi depositada no laboratório da Embrapa Roraima. As conferências e atualizaçóes da nomenclatura botânica foram realizadas mediante consulta ao banco de dados do Missouri Botanical Garden (Mobot 2011). As espécies foram classificadas pelo sistema proposto pelo Angiosperm Phylogeny Group (APG III 2009).

A diversidade foi calculada mediante o emprego do índice de Shannon ( $\left.\mathrm{H}^{\prime}\right)$, na base logarítmica natural, e a uniformidade através da equabilidade de Pielou (J), conforme Magurran (1988). Na análise da estrutura horizontal foram considerados os seguintes parâmetros para cada espécie: Densidade Absoluta (DA) e Densidade Relativa (DR); Dominância Absoluta (DoA) e Dominância Relativa (DoR); Frequência Absoluta (FA), Frequência Relativa (FR) e Valor de Importância (VI), conforme recomendado por MüllerDombois e Ellemberg (1974). A importância ecológica das famílias no ecossistema florestal foi estimada a partir do Índice de Valor de Importância Familiar (IVIF), que foi obtido através da soma da diversidade ( $\mathrm{n}^{\circ}$ de espécies da família / ${ }^{\circ}$ total de espécies), densidade e dominância relativas (Mori e Boom 1983).

Para analisar a estrutura vertical, a floresta foi classificada em três estratos verticais de altura total (HT), conforme descrito por Souza et al. (2003): estrato inferior (EI) - árvores com $\mathrm{HT}<\left(\mathrm{H}_{\mathrm{m}}-1 \sigma\right)$; estrato médio $(\mathrm{EM})$ - árvores com $\left(\mathrm{H}_{\mathrm{m}}\right.$ $-1 \sigma) \leq \mathrm{HT}<\left(\mathrm{H}_{\mathrm{m}}+1 \sigma\right)$; estrato superior $(\mathrm{ES})$ - árvores com $\mathrm{HT} \geq\left(\mathrm{H}_{\mathrm{m}}+1 \sigma\right)$, onde $\mathrm{H}_{\mathrm{m}}$ é a média e $\sigma$ é o desvio padrão das alturas totais (HT) dos indivíduos amostrados. Todos os indivíduos foram mensurados em altura e distância horizontal utilizando (Vertex IV - Haglöf), com exceção das palmeiras, que náo tiveram suas alturas mensuradas. Visando avaliar a importância ecológica das espécies arbóreas através de sua representatividade na estrutura vertical da floresta amostrada, foram geradas estimativas dos parâmetros de Posiçáo Sociológica Absoluta (PSA) e Posição Sociológica Relativa (PSR) por espécie (i), mediante as expressões (Finol 1971):

$$
\mathrm{PSA}_{\mathrm{i}}=\sum_{\mathrm{j}=1}^{\mathrm{J}}\left(\frac{\mathrm{N}_{\mathrm{j}}}{\mathrm{N}}\right) \cdot \mathrm{N}_{\mathrm{ij}} \quad \mathrm{PSR}_{\mathrm{i}}=\frac{\mathrm{PSA}_{\mathrm{i}}}{\sum_{\mathrm{i}=1}^{\mathrm{S}} \mathrm{PSA}_{\mathrm{i}}} \cdot 100
$$

Em que:

$$
\mathrm{N}_{\mathrm{j}} \text { = número de indivíduos do i-ésimo estrato; }
$$

$\mathrm{N}$ = número total de indivíduos de todas as espécies, em todos os estratos;

$\mathrm{N}_{\mathrm{ij}}$ = número de indivíduos da i-ésima espécie no j-ésimo estrato de altura;

$S=$ número total de espécies amostradas.

Todas as espécies foram classificadas conforme o grupo sucessional, segundo a classificação de Budowski (1965): pioneiras (espécies de crescimento geralmente rápido, encontradas principalmente em clareiras); secundárias (espécies de crescimento geralmente moderado, encontradas principalmente em florestas em fase de regeneração) e climácicas ou clímax (espécies de crescimento geralmente lento, encontradas em florestas maduras); para isso foram reunidas informaçóes disponíveis na literatura (Lorenzi 1992; Parrotta et al. 1995; Lorenzi 2002).

\section{RESULTADOS}

\section{Composição Florística}

Foram amostrados 4.724 indivíduos (525 ind.ha ${ }^{-1}$ ), distribuídos em 42 famílias botânicas, 111 gêneros e 165 espécies (Tabela 1). Foram encontradas 40 "espécies raras" ou "localmente raras" (24\%). As famílias botânicas que apresentaram maior número de indivíduos foram: Fabaceae (1.883), Lecythidaceae (609), Sapotaceae (434), perfazendo $52 \%$ do total de indivíduos amostrados.

Com relação à riqueza de espécies, as famílias com maior representatividade foram: Fabaceae (33), Sapotaceae (11), Apocynaceae (9), Moraceae (8), Lauraceae (8), Annonaceae (7), Chrysobalanaceae (7), Lecythidaceae (7) e Urticaceae (7). As cinco famílias que apresentaram maior quantidade de gêneros distintos foram: Fabaceae (22), Sapotaceae (5), Apocynaceae (5), Moraceae (5) e Lecythidaceae (5).

\section{Estrutura e Classificação Ecológica das Espécies}

As espécies Pentaclethra macroloba (52,06), Eschweilera bracteosa $(23,72)$ e Pouteria caimito $(8,10)$ apresentaram os maiores valores de importância, perfazendo $28 \%$ do VI total (Tabela 2). Com relação ao Índice de Valor de Importância Familiar (IVIF), os cinco maiores valores foram alcançados por Fabaceae $(93,2)$, Lecythidaceae $(34,8)$, Sapotaceae $(29,4)$, Lauraceae $(13,1)$ e Chrysobalanaceae $(12,6)$ que, somados, perfazem $61 \%$ do IVIF total (Tabela 3). Fabaceae obteve também os maiores valores de PSR (42,4\%), DR (39,9\%), DoR $(33,3 \%)$ e DIVR (20,0\%).

A floresta foi classificada em três estratos verticais: estrato inferior (EI, no qual $\mathrm{HT}<12,41 \mathrm{~m}$ ); estrato médio (EM, $12,41 \leq \mathrm{HT}<26,46$ ) e estrato superior (ES, HT $\geq 26,46$ ). As espécies que tiveram os maiores valores de PSR foram: Pentaclethra macroloba (34,6\%), Eschweilera bracteosa (11,5\%) e Pouteria caimito $(4,6 \%)$ (Tabela 2$)$. 
Tabela 1 - Estimativas dos parâmetros fitossociológicos e categorias sucessionais das espécies arbóreas amostradas na Floresta Ombrófila Densa em Caracaraí, Roraima, Brasil.

\begin{tabular}{|c|c|c|c|c|c|c|c|}
\hline Família/Espécie & Nome popular & $\mathrm{N}$ & CS & El & EM & ES & $\mathrm{VI}$ \\
\hline Anacardiaceae & & 18 & & & & & \\
\hline Anacardium giganteum W. Hancock ex Engl. & Cajuí & 10 & $\mathrm{CL}$ & 1 & 7 & 2 & 1,80 \\
\hline Tapirira guianensis Aubl. & Pau-pombo & 8 & PI & 2 & 6 & 0 & 1,02 \\
\hline Annonaceae & & 172 & & & & & \\
\hline Annona ambotay Aubl. & Araticum-do-mato & 1 & $\mathrm{Pl}$ & 1 & 0 & 0 & 0,18 \\
\hline Annona haematantha Miq. & Araticum & 1 & $\mathrm{PI}$ & 1 & 0 & 0 & 0,18 \\
\hline Bocageopsis multiflora ( Mart. ) R.E. Fr & Envira-surucucú & 35 & SE & 1 & 33 & 1 & 2,49 \\
\hline Guatteria citriodora Ducke & Invira-amarela & 1 & SE & 1 & 0 & 0 & 0,18 \\
\hline Guatteria discolor R.E. Fr. & Invira-branca & 5 & SE & 0 & 5 & 0 & 0,74 \\
\hline Guatteria guianensis (Aubl.) R.E. Fr. & Invira-preta & 7 & SE & 0 & 6 & 1 & 0,71 \\
\hline Xylopia parviflora Spruce & Envira-sarará & 122 & PI & 2 & 93 & 27 & 5,39 \\
\hline Apocynaceae & & 95 & & & & & \\
\hline Ambelania acida Aubl. & Pepino-do-mato & 28 & SE & 9 & 18 & 1 & 1,96 \\
\hline Aspidosperma album (Vahl) Benoist ex Pichon & Pequiá-marfim & 4 & $\mathrm{CL}$ & 0 & 2 & 2 & 0,81 \\
\hline Aspidosperma desmanthum Benth. ex Müll. Arg. & Araracanga & 1 & $\mathrm{CL}$ & 0 & 0 & 1 & 0,28 \\
\hline Aspidosperma nitidum Benth. & Carapanaúba & 9 & SE & 2 & 5 & 2 & 1,70 \\
\hline Aspidosperma spruceanum Benth. ex Müll. Arg. & Pau-marfim & 3 & SE & 0 & 3 & 0 & 0,39 \\
\hline Geissospermum argenteum Woodson & Quina-quina & 1 & SE & 1 & 0 & 0 & 0,18 \\
\hline Geissospermum sericeum Miers & Quinarana & 45 & SE & 6 & 36 & 3 & 3,79 \\
\hline Himatanthus sucuuba (Spruce ex Müll. Arg.) Woodson & Sucuuba & 2 & SE & 0 & 2 & 0 & 0,39 \\
\hline Tabernaemontana angulata Mart. ex Mull. Arg. & Pimenta-de-lontra & 2 & SE & 2 & 0 & 0 & 0,35 \\
\hline Araliaceae & & 2 & & & & & \\
\hline Schefflera morototoni (Aubl.) Decne. \& Planch. & Morototó & 2 & SE & 0 & 1 & 1 & 0,52 \\
\hline Arecaceae & & 254 & & & & & \\
\hline Astrocaryum aculeatum G. Mey. & Tucumã & 2 & SE & - & - & - & 0,37 \\
\hline Euterpe precatoria Martius & Açaí-solteiro & 89 & SE & - & - & - & 3,70 \\
\hline Maximiliana maripa (Aubl.) Drude & Inajá & 10 & SE & - & - & - & 1,20 \\
\hline Oenocarpus bacaba Martius & Bacaba & 146 & SE & - & - & - & 0,78 \\
\hline Oenocarpus bataua Martius & Patuá & 5 & SE & - & - & - & 5,68 \\
\hline Socratea exorrhiza (Mart.) H. Wendl. & Pachiúba & 2 & $\mathrm{CL}$ & - & - & - & 0,20 \\
\hline Bignoniaceae & & 33 & & & & & \\
\hline Jacaranda copaia (Aubl.) D. Don. & Caroba & 33 & $\mathrm{PI}$ & 2 & 25 & 6 & 2,66 \\
\hline Boraginaceae & & 14 & & & & & \\
\hline Cordia goeldiana Huber & Freijó-branco & 14 & SE & 2 & 12 & 0 & 1,34 \\
\hline Burseraceae & & 161 & & & & & \\
\hline Crepidospermum rhoifolium ( Benth. ) Triana \& Planch. & Breu & 73 & SE & 13 & 59 & 1 & 3,56 \\
\hline Protium apiculatum Swart & Breu-vermelho & 1 & SE & 0 & 1 & 0 & 0,18 \\
\hline Protium robustum (Swart) D.M. Porter & Breu-folha-larga & 2 & SE & 0 & 2 & 0 & 0,36 \\
\hline Protium trifoliolatum Engl. & Breu-peludo & 69 & SE & 7 & 54 & 8 & 3,88 \\
\hline Trattinnickia peruviana Loes. & Breu branco & 1 & $\mathrm{PI}$ & 1 & 0 & 0 & 0,18 \\
\hline Trattinnickia rhoifolia Willd. & Breu-manga & 15 & $\mathrm{PI}$ & 1 & 13 & 1 & 2,01 \\
\hline Caryocaraceae & & 1 & & & & & \\
\hline Caryocar glabrum Pers. & Pequiá & 1 & $\mathrm{CL}$ & 0 & 0 & 1 & 0,52 \\
\hline Celastraceae & & 2 & & & & & \\
\hline Maytenus guianensis Klotzsch & Chichuá & 2 & SE & 1 & 1 & 0 & 0,38 \\
\hline
\end{tabular}


Tabela 1 - Continuação

\begin{tabular}{|c|c|c|c|c|c|c|c|}
\hline Família/Espécie & Nome popular & $\mathrm{N}$ & CS & El & EM & ES & VI \\
\hline Chrysobalanaceae & & 225 & & & & & \\
\hline Couepia bracteosa Benth. & Batinga & 7 & SE & 0 & 1 & 6 & 1,60 \\
\hline Hirtella racemosa Lam. & Caraipé-branco & 5 & SE & 2 & 3 & 0 & 0,77 \\
\hline Licania adolphoduckei Prance & Macucu & 1 & $\mathrm{CL}$ & 0 & 0 & 1 & 0,35 \\
\hline Licania apetala (E. Mey.) Fritsch. & Caraipé & 145 & $\mathrm{CL}$ & 19 & 122 & 4 & 6,03 \\
\hline Licania heteromorpha Benth. & Macacuí & 64 & SE & 0 & 54 & 10 & 3,87 \\
\hline Licania Iongistyla ( Hook. f. ) Fritsch. & Caraiperana & 1 & $\mathrm{CL}$ & 0 & 1 & 0 & 0,18 \\
\hline Licania micrantha Miq. & Pintadinho & 2 & SE & 0 & 2 & 0 & 0,38 \\
\hline Clusiaceae & & 1 & & & & & \\
\hline Garcinia macrophylla Martius & Bacuri & 1 & $\mathrm{CL}$ & 0 & 1 & 0 & 0,19 \\
\hline Combretaceae & & 8 & & & & & \\
\hline Buchenavia grandis Ducke & Tanibuca & 6 & SE & 0 & 3 & 3 & 1,13 \\
\hline Buchenavia parvifolia Ducke & Cuiarana & 2 & SE & 0 & 1 & 1 & 1,01 \\
\hline Elaeocarpaceae & & 12 & & & & & \\
\hline Sloanea floribunda Spruce ex Benth. & Urucurana & 9 & SE & 3 & 5 & 1 & 1,21 \\
\hline Sloanea latifolia (Rich.) K. Schum. & Urucuranaçu & 2 & SE & 1 & 1 & 0 & 0,21 \\
\hline Sloanea synandra Spruce ex Benth. & Urucurana-branca & 1 & SE & 0 & 1 & 0 & 0,18 \\
\hline Euphorbiaceae & & 51 & & & & & \\
\hline Alchorneopsis floribunda (Benth.) Müll. Arg. & Gaivotinha & 1 & SE & 0 & 1 & 0 & 0,18 \\
\hline Conceveiba guianensis Aubl. & Seringa-de-arara & 8 & SE & 7 & 1 & 0 & 1,14 \\
\hline Croton lanjouwensis Jabl. & Dima & 42 & $\mathrm{PI}$ & 1 & 27 & 14 & 3,80 \\
\hline Fabaceae & & 1883 & & & & & \\
\hline Abarema jupunba (Willd.) Britton \& Killip & Saboeiro & 5 & $\mathrm{PI}$ & 2 & 3 & 0 & 0,65 \\
\hline Bowdichia nitida Spruce ex Benth. & Sucupira-amarela & 1 & $\mathrm{CL}$ & 0 & 0 & 1 & 0,30 \\
\hline Cedrelinga cateniformis (Ducke) Ducke & Cedrorana & 9 & $\mathrm{PI}$ & 0 & 3 & 6 & 1,75 \\
\hline Dialium guianense (Aubl.) Sandwith & Jutaí & 7 & SE & 0 & 3 & 4 & 1,17 \\
\hline Dimorphandra coccinea Ducke & Angico & 1 & $\mathrm{PI}$ & 1 & 0 & 0 & 0,18 \\
\hline Dinizia excelsa Ducke & Angelim-ferro & 6 & $\mathrm{CL}$ & 0 & 2 & 4 & 2,29 \\
\hline Diplotropis martiusii Benth. & Sucupira-preta & 6 & $\mathrm{CL}$ & 2 & 4 & 0 & 0,80 \\
\hline Enterolobium schomburgkii (Benth.) Benth. & Orelha-de-macaco & 8 & SE & 1 & 4 & 3 & 1,25 \\
\hline Hymenaea courbaril L. & Jatobá & 12 & SE & 0 & 6 & 6 & 1,95 \\
\hline Hymenolobium excelsum Ducke & Angelim-pedra & 7 & $\mathrm{CL}$ & 0 & 2 & 5 & 1,80 \\
\hline Hymenolobium heterocarpum Ducke & Mirarema & 14 & SE & 0 & 6 & 8 & 2,47 \\
\hline Hymenolobium sericeum Ducke & Angelim-rajado & 1 & $\mathrm{CL}$ & 0 & 0 & 1 & 0,31 \\
\hline Inga alba (Sw.) Willd. & Ingá-branco & 62 & SE & 4 & 54 & 4 & 3,46 \\
\hline Inga capitata Desv. & Ingá-de-macaco & 49 & SE & 6 & 41 & 2 & 2,70 \\
\hline Inga laurina (Sw.) Willd. & Ingá-chichica & 7 & $\mathrm{PI}$ & 4 & 3 & 0 & 0,94 \\
\hline Inga longiflora Spruce ex Benth. & Ingarana & 18 & $\mathrm{PI}$ & 1 & 14 & 3 & 1,15 \\
\hline Inga pezizifera Benth. & Ingá-vermelho & 1 & $\mathrm{PI}$ & 0 & 0 & 1 & 0,35 \\
\hline Macrolobium limbatum Spruce ex Benth. & Iperana & 1 & SE & 0 & 1 & 0 & 0,18 \\
\hline Ormosia paraensis Ducke & Tento & 1 & SE & 0 & 0 & 1 & 0,20 \\
\hline Ormosia sp. & Tento-preto & 1 & SE & 0 & 1 & 0 & 0,18 \\
\hline Parkia multijuga Benth. & Angelim-saia & 14 & SE & 0 & 10 & 4 & 1,53 \\
\hline Parkia nitida Miq. & Faveira-branca & 1 & SE & 0 & 1 & 0 & 0,20 \\
\hline Parkia pendula (Willd.) Benth. ex Walp. & Fava-bolota & 9 & SE & 0 & 4 & 5 & 1,77 \\
\hline Pentaclethra macroloba (Willd.) Kuntze & Paracaxi & 1496 & $\mathrm{PI}$ & 243 & 1198 & 55 & 52,06 \\
\hline
\end{tabular}


Tabela 1 - Continuação

\begin{tabular}{|c|c|c|c|c|c|c|c|}
\hline Família/Espécie & Nome popular & N & CS & $\mathrm{El}$ & EM & ES & $\mathrm{VI}$ \\
\hline Piptadenia poeppigii (Poepp.) Klotzsch ex Benth. & Cambará & 24 & SE & 1 & 15 & 8 & 2,29 \\
\hline Platymiscium duckei Huber & Macacaúba & 1 & SE & 0 & 0 & 1 & 0,19 \\
\hline Pseudopiptadenia psilostachya (DC.) G. P. Lewis \& M. P. Lima & Angico-branco & 34 & $\mathrm{PI}$ & 0 & 14 & 20 & 3,65 \\
\hline Sclerolobium guianense Benth. & Tachi-preto & 73 & $\mathrm{Pl}$ & 3 & 58 & 12 & 5,09 \\
\hline Stryphnodendron guianense ( Aubl.) Benth. & Faveira-camusé & 4 & $\mathrm{PI}$ & 1 & 3 & 0 & 0,43 \\
\hline Swartzia corrugata Benth. & Piritó & 1 & $\mathrm{CL}$ & 0 & 1 & 0 & 0,40 \\
\hline Swartzia ingifolia Ducke & Carrapatinho & 2 & $\mathrm{CL}$ & 1 & 1 & 0 & 0,22 \\
\hline Swartzia reticulata Ducke & Coração-de-negro & 1 & $\mathrm{CL}$ & 1 & 0 & 0 & 0,18 \\
\hline Vatairea guianensis Aubl. & Angelim- amargoso & 6 & $\mathrm{CL}$ & 1 & 3 & 2 & 1,29 \\
\hline Goupiaceae & & 41 & & & & & \\
\hline Goupia glabra Aubl. & Cupiúba & 41 & $\mathrm{PI}$ & 0 & 15 & 26 & 5,41 \\
\hline Humiriaceae & & 4 & & & & & \\
\hline Endopleura uchi (Huber) Cuatrec. & Uichi-liso & 1 & $\mathrm{CL}$ & 0 & 1 & 0 & 0,21 \\
\hline Sacoglottis guianensis Benth. & Uichi-de-morcego & 3 & SE & 0 & 2 & 1 & 0,45 \\
\hline Icacinaceae & & 26 & & & & & \\
\hline Poraqueiba guianensis Aubl. & Mari-bravo & 26 & SE & 0 & 23 & 3 & 2,35 \\
\hline Lacistemataceae & & 1 & & & & & \\
\hline Lacistema aggregatum (P.J. Bergius) Rusby & Apuizinho & 1 & SE & 0 & 1 & 0 & 0,18 \\
\hline Lauraceae & & 184 & & & & & \\
\hline Aniba ferrea Kubitzki & Louro-ferro & 1 & $\mathrm{CL}$ & 0 & 1 & 0 & 0,19 \\
\hline Licaria aritu Ducke & Louro-aritu & 39 & SE & 1 & 29 & 9 & 3,27 \\
\hline Licaria chrysophylla (Meisn.) Kosterm. & Louro-cravo & 90 & SE & 17 & 67 & 6 & 4,15 \\
\hline Ocotea matogrossensis Vatt. & Louro-abacate & 7 & $\mathrm{CL}$ & 2 & 5 & 0 & 0,83 \\
\hline Ocotea aciphylla ( Nees ) Mez & Canelinha & 1 & $\mathrm{CL}$ & 1 & 0 & 0 & 0,18 \\
\hline Ocotea cinerea van der Werff & Louro-preto & 41 & $\mathrm{CL}$ & 3 & 25 & 13 & 4,42 \\
\hline Ocotea minor Vicentini & Canela-da-mata & 1 & $\mathrm{CL}$ & 1 & 0 & 0 & 0,18 \\
\hline Ocotea nitida ( Meisn. ) Rohwer & Louro-amarelo & 4 & $\mathrm{CL}$ & 0 & 4 & 0 & 0,41 \\
\hline Lecythidaceae & & 609 & & & & & \\
\hline Bertholletia excelsa Humb. \& Bonpl. & Castanha-do-Brasil & 14 & SE & 0 & 3 & 11 & 5,81 \\
\hline Couratari longipedicellata W.A. Rodrigues & Estopeiro & 2 & $\mathrm{CL}$ & 1 & 0 & 1 & 0,64 \\
\hline Couratari stellata A.C. Sm. & Tauari & 2 & $\mathrm{CL}$ & 0 & 0 & 2 & 0,63 \\
\hline Eschweilera atropetiolata S.A.Mori & Castanharana & 61 & $\mathrm{CL}$ & 4 & 44 & 13 & 4,05 \\
\hline Eschweilera bracteosa (Poepp. ex 0. Berg) Miers & Mata-matá-amarelo & 528 & $\mathrm{CL}$ & 49 & 392 & 87 & 23,72 \\
\hline Gustavia hexapetala ( Aubl. ) Sm. & General & 1 & SE & 0 & 1 & 0 & 0,18 \\
\hline Lecythis prancei S.A. Mori & Jarana-amarela & 1 & $\mathrm{CL}$ & 0 & 1 & 0 & 0,18 \\
\hline Malvaceae & & 46 & & & & & \\
\hline Apeiba echinata Gaertn. & Invira-pente- macaco & 36 & $\mathrm{Pl}$ & 1 & 34 & 1 & 2,53 \\
\hline Eriotheca globosa (Aubl.) A. Robyns & Paineira & 6 & SE & 0 & 5 & 1 & 0,98 \\
\hline Lueheopsis rosea ( Ducke) Burret & Açoita-cavalo & 3 & SE & 0 & 2 & 1 & 0,61 \\
\hline Theobroma subincanum Mart. & Cupuí & 1 & $\mathrm{CL}$ & 0 & 1 & 0 & 0,18 \\
\hline Melastomataceae & & 15 & & & & & \\
\hline Miconia argyrophylla DC. & Bochuchu & 1 & $\mathrm{Pl}$ & 0 & 0 & 1 & 0,19 \\
\hline Mouriri angulicosta Morley & Muiraúba & 13 & SE & 5 & 8 & 0 & 1,11 \\
\hline Mouriri duckeana Morley & Muriri & 1 & SE & 1 & 0 & 0 & 0,18 \\
\hline Meliaceae & & 7 & & & & & \\
\hline Guarea convergens T.D. Penn. & Cedrinho-Jitó & 7 & SE & 2 & 5 & 0 & 0,65 \\
\hline
\end{tabular}


Tabela 1 - Continuação

\begin{tabular}{|c|c|c|c|c|c|c|c|}
\hline Família/Espécie & Nome popular & $\mathrm{N}$ & CS & $\mathrm{El}$ & EM & ES & $\mathrm{VI}$ \\
\hline Monimiaceae & & 15 & & & & & \\
\hline Siparuna cuspidata ( Tul. ) A.DC. & Capitiú & 15 & SE & 3 & 12 & 0 & 1,20 \\
\hline Moraceae & & 81 & & & & & \\
\hline Brosimum parinarioides Ducke & Amapá & 1 & SE & 0 & 1 & 0 & 0,18 \\
\hline Brosimum rubescens Taub. & Pau-rainha & 10 & SE & 0 & 8 & 2 & 1,40 \\
\hline Clarisia racemosa Ruiz \& Pav. & Guariúba & 9 & $\mathrm{CL}$ & 0 & 7 & 2 & 1,31 \\
\hline Ficus obtusifolia Kunth & Figueira-apuí & 6 & SE & 0 & 1 & 5 & 1,42 \\
\hline Ficus trigona L. f. & Figueira & 1 & SE & 0 & 0 & 1 & 0,20 \\
\hline Naucleopsis caloneura ( Huber) Ducke & Muiratinga & 51 & SE & 7 & 39 & 5 & 3,08 \\
\hline Sorocea guilleminiana Gaudich. & Jaca-brava & 2 & $\mathrm{CL}$ & 2 & 0 & 0 & 0,36 \\
\hline Sorocea muriculata Miq. & Língua-de-tucano & 1 & $\mathrm{CL}$ & 1 & 0 & 0 & 0,18 \\
\hline Myristicaceae & & 189 & & & & & \\
\hline Iryanthera paradoxa (Schwacke ) Warb. & Ucuuba-punã & 61 & $\mathrm{CL}$ & 6 & 52 & 3 & 3,49 \\
\hline Virola calophylla (Spruce) Warb. & Ucuuba-vermelha & 78 & SE & 14 & 62 & 2 & 3,62 \\
\hline Virola michelii Heckel & Ucuuba-preta & 50 & SE & 1 & 42 & 7 & 3,28 \\
\hline Myrtaceae & & 9 & & & & & \\
\hline Calyptranthes crebra McVaugh & Araçá & 3 & SE & 0 & 3 & 0 & 0,54 \\
\hline Calyptranthes cuspidata DC. & Araçá-do-mato & 1 & SE & 1 & 0 & 0 & 0,18 \\
\hline Eugenia biflora (L.) DC. & Murtinha & 1 & SE & 0 & 1 & 0 & 0,18 \\
\hline Myrcia huallagae McVaugh & Goiaba-do-mato & 3 & SE & 1 & 2 & 0 & 0,53 \\
\hline Myrcia rufipila McVaugh. & Araçá-bravo & 1 & SE & 0 & 1 & 0 & 0,19 \\
\hline Ochnaceae & & 7 & & & & & \\
\hline Lacunaria jenmanii (Oliv.) Ducke & Fruta-de-mutum & 1 & $\mathrm{CL}$ & 1 & 0 & 0 & 0,19 \\
\hline Quiina negrensis A.C. Sm. & Moela-de-mutum & 6 & SE & 2 & 4 & 0 & 0,93 \\
\hline Olacaceae & & 2 & & & & & \\
\hline Chaunochiton kappleri (Sagot ex Engl.) Ducke & Pau-vermelho & 2 & $\mathrm{CL}$ & 0 & 1 & 1 & 0,39 \\
\hline Rubiaceae & & 9 & & & & & \\
\hline Duroia eriopila L. f. & Apuruí & 9 & SE & 0 & 9 & 0 & 0,42 \\
\hline Rutaceae & & 2 & & & & & \\
\hline Nycticalanthus speciosus Ducke & Folha-de-espada & 1 & $\mathrm{CL}$ & 0 & 1 & 0 & 0,18 \\
\hline Zanthoxylum rhoifolium Lam. & Tamanqueira & 1 & SE & 0 & 1 & 0 & 0,18 \\
\hline Salicaceae & & 4 & & & & & \\
\hline Casearia javitensis Kunth. & Cafezeiro-do-mato & 1 & SE & 0 & 1 & 0 & 0,18 \\
\hline Laetia procera (Poepp.)Eichler. & Pau-jacaré & 3 & SE & 0 & 1 & 2 & 0,70 \\
\hline Sapindaceae & & 29 & & & & & \\
\hline Toulicia guianensis Aubl. & Pitomba-brava & 29 & SE & 1 & 27 & 1 & 2,06 \\
\hline Sapotaceae & & 434 & & & & & \\
\hline Chrysophyllum prieurii A. DC. & Maçarandubarana & 1 & SE & 1 & 0 & 0 & 0,18 \\
\hline Ecclinusa guianensis Eyma & Abiurana-bacuri & 3 & SE & 0 & 1 & 2 & 0,39 \\
\hline Lucuma speciosa Ducke & Abacatão & 76 & SE & 3 & 41 & 32 & 7,36 \\
\hline Manilkara huberi (Ducke) A. Chev. & Maçaranduba & 55 & $\mathrm{CL}$ & 2 & 27 & 26 & 6,96 \\
\hline Micropholis guyanensis (A. DC.) Pierre & Balata & 73 & SE & 3 & 62 & 8 & 3,84 \\
\hline Micropholis venulosa (Mart. \& Eichler) Pierre & Balatinha & 5 & SE & 1 & 3 & 1 & 0,88 \\
\hline Pouteria anomala (Pires) T.D.Penn. & Abiurana-roxa & 1 & SE & 0 & 1 & 0 & 0,19 \\
\hline Pouteria caimito (Ruiz \& Pav.) Radlk. & Abiurana- vermelha & 188 & SE & 15 & 162 & 11 & 8,10 \\
\hline Pouteria elegans (A. DC.) Baehni & Abiurana-branca & 7 & SE & 1 & 4 & 2 & 0,97 \\
\hline Pouteria hispida Eyma & Abiu-branco & 24 & SE & 0 & 20 & 4 & 2,12 \\
\hline
\end{tabular}


Tabela 1 - Continuação

\begin{tabular}{|c|c|c|c|c|c|c|c|}
\hline Família/Espécie & Nome popular & $\mathrm{N}$ & CS & El & EM & ES & $\mathrm{VI}$ \\
\hline Pouteria peruviensis (Aubrév.) Bernardi & Abiurana-ferro & 1 & SE & 0 & 1 & 0 & 0,18 \\
\hline Simaroubaceae & & 6 & & & & & \\
\hline Simarouba amara Aubl. & Marupá & 6 & SE & 2 & 2 & 2 & 1,09 \\
\hline Stemonuraceae & & 1 & & & & & \\
\hline Discophora guianensis Miers & Pombinho & 1 & SE & 0 & 1 & 0 & 0,19 \\
\hline Ulmaceae & & 3 & & & & & \\
\hline Ampelocera edentula Kuhlm. & Ampelocera & 3 & SE & 1 & 2 & 0 & 0,55 \\
\hline Urticaceae & & 21 & & & & & \\
\hline Cecropia purpurascens C.C. Berg. & Embaúba-branca & 1 & $\mathrm{Pl}$ & 0 & 1 & 0 & 0,19 \\
\hline Cecropia sciadophylla Martius & Embaúba-brava & 7 & $\mathrm{PI}$ & 0 & 6 & 1 & 1,03 \\
\hline Coussapoa latifolia Aubl. & Mata-pau & 1 & SE & 0 & 0 & 1 & 0,19 \\
\hline Coussapoa orthoneura Standl. & Figueirinha & 1 & SE & 0 & 0 & 1 & 0,19 \\
\hline Pourouma guianensis Aubl. & Embaúba-torém & 8 & $\mathrm{PI}$ & 0 & 6 & 2 & 0,75 \\
\hline Pourouma myrmecophila Ducke & Embaúba-formiga & 1 & $\mathrm{PI}$ & 1 & 0 & 0 & 0,18 \\
\hline Pourouma tomentosa Mart. ex Miq. & Embaúba-da-mata & 2 & $\mathrm{PI}$ & 1 & 1 & 0 & 0,36 \\
\hline Violaceae & & 21 & & & & & \\
\hline Leonia glycycarpa Ruiz \& Pav. & Catoré-branco & 3 & SE & 1 & 2 & 0 & 0,57 \\
\hline Rinorea macrocarpa (Mart.) Kuntze & Canela-de-velho & 18 & SE & 9 & 9 & 0 & 1,23 \\
\hline Vochysiaceae & & 26 & & & & & \\
\hline Erisma bracteosum Ducke & Quaruba & 3 & $\mathrm{CL}$ & 0 & 3 & 0 & 0,58 \\
\hline Erisma fuscum Ducke & Caferana & 6 & $\mathrm{CL}$ & 0 & 4 & 2 & 1,47 \\
\hline Qualea paraensis Ducke & Rabo-de-arraia & 11 & $\mathrm{CL}$ & 0 & 1 & 10 & 2,58 \\
\hline Vochysia biloba Ducke & Quarubarana & 6 & $\mathrm{CL}$ & 0 & 0 & 6 & 1,66 \\
\hline Total geral & & 4724 & & & & & \\
\hline
\end{tabular}

$\mathrm{N}=$ número de indivíduos; $\mathrm{CS}=$ Classe sucessional (PI: Pioneira, SE: Secundária, CL: Clímácica); El = estrato inferior (HT < 12,41 m); EM = estrato médio (12,41 m $\leq$ HT < $26,46 \mathrm{~m}) ; \mathrm{ES}=$ estrato superior $(\mathrm{HT} \geq 26,46 \mathrm{~m}) ; \mathrm{VI}=$ valor de importância (DR +FR+DoR).

Tabela 2 - Relação das espécies arbóreas inventariadas e suas respectivas estimativas dos parâmetros na Floresta Ombrófila Densa em Caracaraí, Roraima, Brasil, em ordem decrescente de VI.

\begin{tabular}{|c|c|c|c|c|c|c|c|c|c|c|}
\hline \multirow{2}{*}{ Espécie } & \multirow{2}{*}{$\mathrm{N}$} & \multicolumn{2}{|c|}{ Vertical } & \multicolumn{7}{|c|}{ Horizontal } \\
\hline & & PSA & PSR & $\mathrm{DA}$ & $\mathrm{DR}$ & DoA & DoR & FA & FR & VI \\
\hline Pentaclethra macroloba & 1496 & 901 & 34,6 & 166,2 & 31,7 & 4,7 & 19,0 & 100 & 1,4 & 52,1 \\
\hline Eschweilera bracteosa & 528 & 298 & 11,5 & 58,7 & 11,2 & 2,8 & 11,2 & 100 & 1,4 & 23,7 \\
\hline Pouteria caimito & 188 & 119 & 4,6 & 20,9 & 4,0 & 0,7 & 2,8 & 100 & 1,4 & 8,1 \\
\hline Lucuma speciosa & 76 & 34 & 1,3 & 8,4 & 1,6 & 1,1 & 4,4 & 100 & 1,4 & 7,4 \\
\hline Manilkara huberi & 55 & 23 & 0,9 & 6,1 & 1,2 & 1,1 & 4,4 & 100 & 1,4 & 7,0 \\
\hline Licania apetala & 145 & 91 & 3,5 & 16,1 & 3,1 & 0,4 & 1,6 & 100 & 1,4 & 6,0 \\
\hline Bertholletia excelsa & 14 & 3 & 0,1 & 1,6 & 0,3 & 1,1 & 4,5 & 78 & 1,1 & 5,8 \\
\hline Oenocarpus bacaba & 146 & 24 & 0,9 & 16,2 & 3,1 & 0,3 & 1,2 & 100 & 1,4 & 5,7 \\
\hline Goupia glabra & 41 & 14 & 0,5 & 4,6 & 0,9 & 0,8 & 3,2 & 100 & 1,4 & 5,4 \\
\hline Sub-Totais & 2689 & 1508 & 58,0 & 298,8 & 56,9 & 12,9 & 52,3 & 877,8 & 11,9 & 121,1 \\
\hline Outras espécies & 2035 & 1094 & 42,0 & 226,1 & 43,1 & 11,7 & 47,7 & 6500,0 & 88,1 & 178,9 \\
\hline Total & 4724 & 2601 & 100 & 524,9 & 100 & 24,6 & 100 & 7377,8 & 100 & 300 \\
\hline
\end{tabular}

$\mathrm{N}$ = número de indivíduos; PSA = posição sociológica absoluta; $\mathrm{PSR}=$ posição sociológica relativa; $\mathrm{DA}=$ densidade absoluta; $\mathrm{DR}=$ densidade relativa; DoA = dominância absoluta; $D 0 R=$ dominância relativa; $F A=$ frequência absoluta; $F R=$ frequência relativa; $V I=$ valor de importância $(D R+F R+D o R)$ 
Tabela 3 - Relação das famílias botânicas inventariadas e suas respectivas estimativas dos parâmetros na Floresta Ombrófila Densa em Caracaraí, Roraima, Brasil, em ordem decrescente de IVIF.

\begin{tabular}{|c|c|c|c|c|c|c|c|c|c|c|}
\hline \multirow{2}{*}{ Família } & \multirow{2}{*}{$\mathrm{N}$} & \multicolumn{2}{|c|}{ Vertical } & \multicolumn{7}{|c|}{ Horizontal } \\
\hline & & PSA & PSR & DA & $\mathrm{DR}$ & DoA & DoR & DIVA & DIVR & IVIF \\
\hline Fabaceae & 1883 & 1101 & 42,4 & 209,2 & 39,9 & 8,2 & 33,3 & 0,20 & 20,0 & 93,19 \\
\hline Lecythidaceae & 609 & 337 & 13,0 & 67,7 & 12,9 & 4,3 & 17,6 & 0,04 & 4,2 & 34,78 \\
\hline Sapotaceae & 434 & 244 & 9,4 & 48,2 & 9,2 & 3,3 & 13,6 & 0,07 & 6,7 & 29,41 \\
\hline Lauraceae & 184 & 101 & 3,9 & 20,4 & 3,9 & 1,1 & 4,3 & 0,05 & 4,8 & 13,05 \\
\hline Chrysobalanaceae & 225 & 136 & 5,2 & 25,0 & 4,8 & 0,9 & 3,6 & 0,04 & 4,2 & 12,60 \\
\hline Arecaceae & 254 & - & - & 28,2 & 5,4 & 0,5 & 2,0 & 0,04 & 3,6 & 11,05 \\
\hline Apocynaceae & 95 & 51,5 & 2,0 & 10,6 & 2,0 & 0,6 & 2,6 & 0,05 & 5,5 & 10,05 \\
\hline Annonaceae & 172 & 102 & 3,9 & 19,1 & 3,6 & 0,5 & 2,0 & 0,04 & 4,2 & 9,87 \\
\hline Burseraceae & 161 & 97 & 3,7 & 17,9 & 3,4 & 0,5 & 2,1 & 0,04 & 3,6 & 9,13 \\
\hline Sub-Totais & 4017 & 2171 & 83,5 & 446,3 & 85,0 & 19,98 & 81,126 & 0,57 & 56,97 & 223,13 \\
\hline Outras famílias & 707 & 430 & 16,5 & 78,6 & 15,0 & 4,6 & 18,9 & 0,43 & 43,0 & 76,87 \\
\hline Total geral & 4724 & 2601 & 100 & 524,9 & 100 & 24,6 & 100 & 1,00 & 100 & 300 \\
\hline
\end{tabular}

$\mathrm{N}=$ número de indivíduos; PSA = posição sociológica absoluta; $P S R=$ posição sociológica relativa; $\mathrm{DA}=$ densidade absoluta; $\mathrm{DR}=$ densidade relativa; DoA = dominância absoluta; DoR = dominância relativa; DIVA = diversidade absoluta; DIVR = diversidade relativa; IVIF = índice de valor de importância familiar (DR + DoR + DIVR).

A classificação sucessional das espécies amostradas resultou na maior densidade do grupo de indivíduos composto por pioneiras (219 ind.ha ${ }^{-1}$ ), em detrimento de secundárias (193 ind.ha ${ }^{-1}$ ) e climácicas (113 ind.ha ${ }^{-1}$ ), no entanto, maior riqueza de espécies foi registrada no grupo das secundárias (95 espécies), em detrimento de climácicas (44) e pioneiras (26). Com relação à distribuição diamétrica das categorias sucessionais, os grupos das pioneiras e secundárias predominaram nas três primeiras classes diamétricas, sendo ultrapassadas pelo grupo de climácicas a partir da sexta classe diamétrica (Figura 1).

\section{Diversidade e uniformidade}

$\mathrm{O}$ índice de diversidade de Shannon (H') encontrado neste estudo foi de 3,27 . O valor de equabilidade de Pielou (J) encontrado neste estudo foi de 0,64. A espécie Pentaclethra

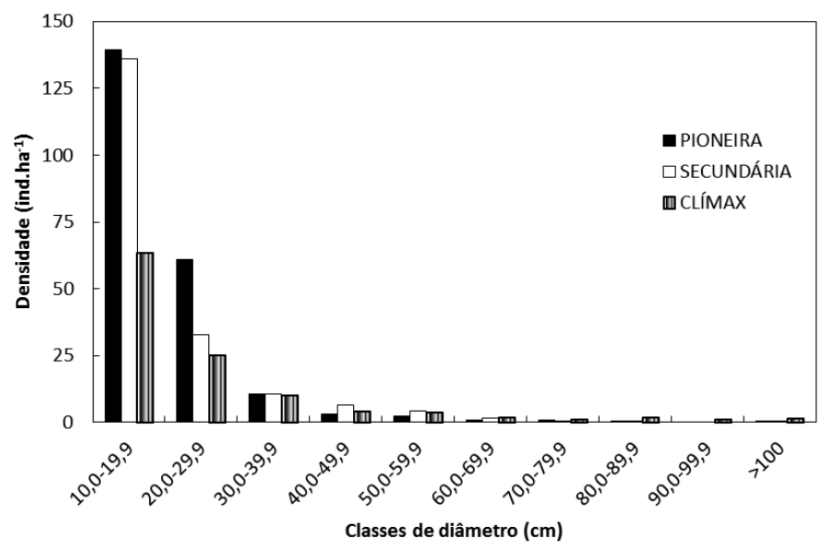

Figura 1 - Frequência de indivíduos por hectare por classe diamétrica por categoria sucessional na Floresta Ombrófila Densa em Caracaraí, Roraima, Brasil. macroloba totalizou 1.496 indíviduos $\left(\bar{N}=166\right.$ ind.ha $\left.^{-1}\right)$, ou seja, $31,7 \%$ do total de indivíduos amostrados, apresentando uma distribuição espacial uniforme na floresta estudada. Foi escolhida aleatoriamente uma das parcelas estudadas para demostrar esse padrão espacial (Figura 2).

\section{DISCUSSÃO}

\section{Composição Florística}

Das "espécies raras" ou "localmente raras" encontradas, ou seja, com apenas um indivíduo por hectare, pode-se citar Cedrelinga cateniformis, Dinizia excelsa, Hymenaea courbaril, Qualea paraensis, Parkia pendula e Conepia bracteosa, apresentadas como espécies de valor comercial dentro do Plano de Manejo Florestal Sustentável da empresa Madeireira Vale Verde Ltda. (Vale Verde 2012).

O percentual de espécies raras encontrado pode ser considerado baixo por se tratar de uma floresta intacta, ou seja, ainda não manejada, principalmente em relação a alguns estudos realizados na Amazônia Legal: 44\% em Oliveira et al. (2003) e 49\% em Silva et al. (2008). Porém cabe salientar, que a intensidade amostral foi de apenas $0,05 \%$ da área de manejo florestal e pode não refletir a quantidade total de espécies raras presentes nessa floresta.

Em relação à riqueza de indivíduos nas famílias botânicas, o resultado deste estudo foi bastante similar ao encontrado por Oliveira e Amaral (2004) em uma floresta de terra firme na Amazônia Central, que também encontraram grande número de indivíduos oriundos das famílias Fabaceae, Lecythidaceae e Sapotaceae.

A maior riqueza de espécies e gêneros pertencentes à Fabaceae neste estudo corrobora com outros estudos realizados 


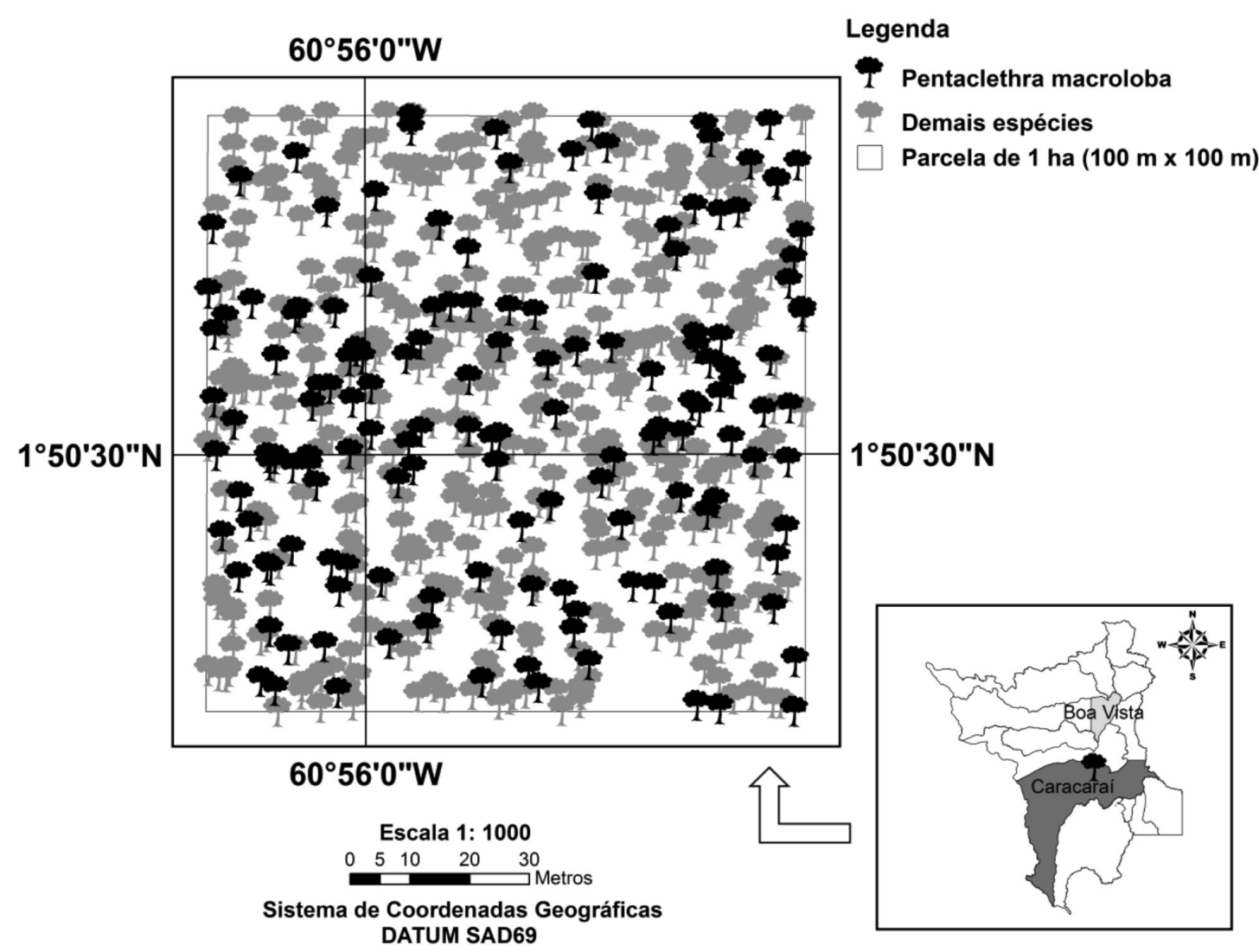

Figura 2 - Distribuição espacial de Pentaclethra macroloba em relação às demais espécies encontradas em uma parcela de um hectare na Floresta Ombrófila Densa em Caracaraí, Roraima, Brasil.

na Amazônia Legal, nos municípios de Caracaraí-RR (Alarcón e Peixoto 2007), Cantá-RR (Silva 2003), Santa Bárbara do Pará-PA (Santos e Jardim 2006) e a $90 \mathrm{~km}$ a nordeste de Manaus-AM (Oliveira et al. 2008).

\section{Estrutura e Classificação Ecológica das Espécies}

O destaque de Pentaclethra macroloba e Eschweilera bracteosa nesta comunidade florestal ocorreu devido aos altos valores encontrados de densidade relativa e dominância relativa. Em um estudo realizado por Santos e Jardim (2006), em floresta de várzea no município de Santa Bárbara do ParáPA, Pentaclethra macroloba alcançou o quinto maior valor de VI $(11,62)$, com $6,79 \%$ de densidade relativa e 4,70\% de dominância relativa. Oliveira e Amaral (2004), em uma floresta de terra firme na Amazônia Central, encontraram o mais alto valor de importância $(9,97)$ para a espécie Eschweilera bracteosa, com $3,89 \%$ de densidade relativa e $3,78 \%$ de dominância relativa.

O resultado encontrado neste estudo para o IVIF (61\% do total) das cinco famílias Fabaceae, Lecythidaceae, Sapotaceae, Lauraceae e Chrysobalanaceae é bastante similar aos obtidos por Oliveira et al. (2008) e Silva et al. (2008). Em relação à estratificação vertical da floresta, a maioria dos indivíduos foi encontrada no EM $\left(71,30 \%=374\right.$ ind.ha $\left.^{-1}\right)$, seguidos por ES $\left(16,6 \%=87\right.$ ind.ha $\left.{ }^{-1}\right)$ e EI $\left(12,11 \%=64\right.$ ind.ha $\left.^{-1}\right)$, indicando que poucos indivíduos conseguem atingir o dossel (ES) da floresta. Embora o número de indivíduos do grupo de pioneiras tenha sido ligeiramente superior aos demais grupos, a floresta estudada apresentou maior riqueza de espécies secundárias, em detrimento de climácicas e pioneiras, podendo ser considerada madura e com boa heterogeneidade de espécies.

O dossel (ES) dessa comunidade florestal apresentou grande quantidade de indivíduos do grupo climácico $(27,6 \%)$, com destaque para a presença de espécies consideradas valiosas para o manejo florestal madeireiro e que geralmente estáo associadas a florestas em estado avançado de sucessão ecológica, como é o caso de Hymenolobium excelsum (5 ind.), Eschweilera bracteosa (87 ind.), Manilkara huberi (26 ind.) Qualea paraensis (10 ind.) e Ocotea cinerea (13 ind.). Poucos indivíduos do grupo de pioneiras ocorreram no dossel $(17,2 \%)$, provavelmente associados a áreas de clareiras ocasionadas por perturbaçóes naturais, como a queda grandes árvores senescentes, sendo espécies típicas dessa condição 
Cecropia sciadophylla (1 ind.), Pentaclethra macroloba (55 ind) e Pourouma guianensis (2 ind).

A presença marcante da pioneira $P$. macroloba no dossel está relacionada a fatores como produçáo precoce de sementes em larga escala (iniciando aos dois anos de idade) com alta taxa de germinação (Joker e Salazar 2000) e extrema eficiência na absorção de nitrogênio (Cavaleri et al. 2006) proporcionando um crescimento muito rápido (Lorenzi 2002).

A distribuição diamétrica dos indivíduos amostrados por hectare foi representada por uma curva decrescente (curva em forma de "J" invertido) que descreve o comportamento padrão em florestas inequiâneas, ou seja, florestas nativas (Oliveira e Amaral 2004; Souza et al. 2006; Gonçalves e Santos 2008).

\section{Diversidade e uniformidade}

$\mathrm{O}$ valor de diversidade $\left(\mathrm{H}^{\prime}=3,27\right)$ encontrado neste estudo está abaixo dos limites esperados para florestas tropicais (Knight 1975), e abaixo do valor obtido em alguns inventários florísticos realizados em Roraima e em outros estados da Amazônia Legal, como por exemplo: 4,66 em 1 ha de parcelas em Caracaraí-RR (Alarcón e Peixoto 2007); 3,39 em 3,6 ha amostrados em transectos e ponto-quadrante de floresta em Cantá-RR (Silva 2003); 4,25 em 1.400,30 ha de parcelas em Almeirim-PA (Alves e Miranda 2008) e 5,10 em 1,0 ha de transectos em Manaus-AM (Oliveira et al. 2008).

Cabe ressaltar que o valor de 3,27 observado neste estudo se deve em grande parte à presença marcante da espécie Pentaclethra macroloba $\left(\bar{N}=166\right.$ ind.ha $\left.{ }^{-1}\right)$, que apresentou uma distribuição espacial uniforme em toda floresta. Para Malheiros et al. (2009), a distinção entre florestas tropicais ocorre, principalmente, pela maior dominância de determinadas espécies na comunidade e por uma baixa semelhança florística ao nível genérico.

Deve-se ressaltar que a riqueza e a diversidade das espécies arbóreas tropicais podem variar conforme a intensidade amostral utilizada. Rolim e Nascimento (1997), ao estudarem as variaçóes no Índice de Shannon em uma comunidade florestal amostrada por censo, simulando diferentes intensidades amostrais, detectaram diferenças significativas para o valor do índice em algumas intensidades, o que indica que estas comparaçóes devem ser realizadas de forma cuidadosa.

A maioria dos estudos sobre a diversidade de espécies arbóreas em florestas tropicais se fundamenta no conceito de área mínima amostral, originado da relação ou curva espécie-área, que é utilizada para estabelecer o tamanho adequado da amostra em diferentes ambientes (Arrhenius 1921; Oliveira et al. 2008). Segundo Schilling e Batista (2008), esse conceito assume que a comunidade vegetal é uma entidade espacialmente discreta, com composição de espécies fixa e definida. Os mesmos autores afirmam que, em florestas tropicais, a definiçấo dos limites das comunidades torna-se particularmente difícil e, devido à alta riqueza de espécies, a curva não apresenta estabilização mesmo com grandes tamanhos de amostra.

Neste estudo a curva espécie-área demonstrou que a amostragem $(9 \mathrm{ha})$ não foi suficiente para a obtenção de um patamar, ou seja, para a estabilização da curva de acumulação de espécies (Figura 3). Já em floresta primária não manejada no município de Prainha-PA, Yared et al. (1998) observaram a estabilização da curva espécie-área ocorrendo entre 2 e 2,5 ha.

$\mathrm{O}$ valor de equabilidade de Pielou $(\mathrm{J}=0,64)$ pode ser considerado relativamente baixo, comparado a outros estudos realizados na Amazônia onde os valores encontram-se entre 0,75 a 0,92 (Kunz et al. 2008; Alves e Miranda, 2008; Oliveira et al. 2008). A baixa equabilidade pode ser atribuída a poucas espécies que ocorreram com elevado número de indivíduos, com destaque para Pentaclethra macroloba.

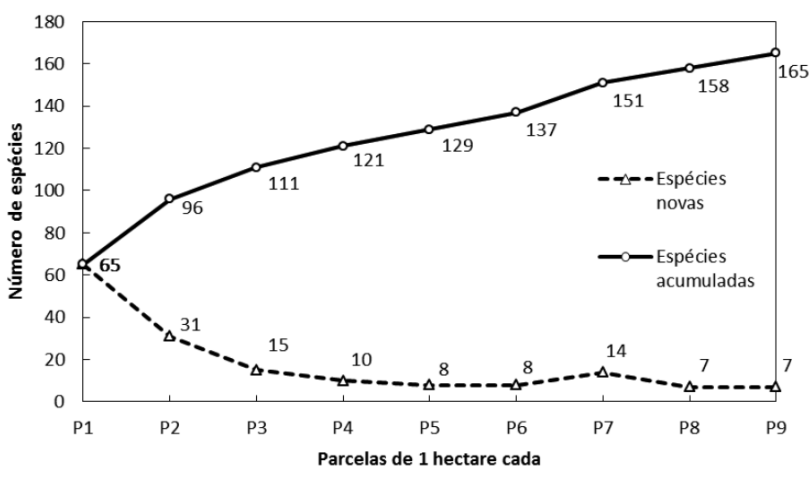

Figura 3 - Curva da relação espécie-área em nove hectares de parcelas permanentes inventariadas na Floresta Ombrófila Densa em Caracaraí, Roraima, Brasil.

\section{CONCLUSÕES}

Baseando-se na composiçáo florística e fitossociológica encontrada nos nove hectares, a floresta nativa ainda não manejada presente na área de manejo florestal em CaracaraíRR, Brasil, pode ser considerada bem estruturada, madura e diversa, caracterizando bom estado de conservaçáo, visto que a heterogeneidade de espécies (165) foi composta principalmente por espécies secundárias (95) e tardias (44).

Porém, foi constatado que a espécie pioneira Pentaclethra macroloba esteve uniformemente presente em todos os estratos verticais da floresta, perfazendo $31,7 \%$ dos indivíduos amostrados, sendo considerada como grande responsável pela reduçáo dos valores dos índices de diversidade (H') e equabilidade $(\mathrm{J})$ na floresta estudada.

A floresta demonstrou boa aptidão para o manejo florestal, contendo espécies de valor comercial (Goupia glabra, 
Qualea paraensis, Manilkara huberi, etc), porém, estratégias de controle populacional devem ser pensadas em relação às espécies de colonizaçấo, estabelecimento e regeneração agressivas como Pentaclethra macroloba.

\section{AGRADECIMENTOS}

Agradecemos o apoio financeiro da Coordenação de Aperfeiçoamento de Pessoal de Nível Superior (Capes), Embrapa Roraima, Programa de Mestrado em Recursos Naturais (PRONAT/UFRR) e também ao apoio logístico da Madeireira Vale Verde Ltda., fundamentais para a realização dessa pesquisa.

\section{BIBLIOGRAFIA CITADA}

Alarcón, J.G.S.; Peixoto, A.L. 2007. Florística e fitossociologia de um trecho de um hectare de floresta de terra firme, em Caracaraí, Roraima, Brasil. Boletim do Museu Paraense Emílio Goeldi, 2: 33-60.

Alves, J.C.Z.O.; Miranda, I.S. 2008. Análise da estrutura de comunidades arbóreas de uma floresta amazônica de Terra Firme aplicada ao manejo florestal. Acta Amazonica, 38: 657-666.

APG III. 2009. An update of the Angiosperm Phylogeny Group classification for the orders and families of flowering plants: APG III. Botanical Journal of the Linnean Society, 161: 2. 105-121.

Archanjo, K.M.P.A.; Silva, G.F.; Chichorro, J.F.; Soares, C.P.B. 2012. Estrutura do componente arbóreo da Reserva Particular do Patrimônio Natural Cafundó, Cachoeiro de Itapemerim, Espírito Santo, Brasil. Floresta, 42: 145-160.

Arrhenius, O. 1921. Species and area. Journal of Ecology, 9: 95-99.

Barni, P.E.; Fearnside, P.M.; Graça, P.M.L.A. 2012. Desmatamento no sul do Estado de Roraima: padrốes de distribuição em funçáo de Projetos de Assentamento do INCRA e da distância das principais rodovias (BR-174 e BR-210). Acta Amazonica, 42: 183-192.

Budowski, G. 1965. Distribution of tropical american rain Forest species in the light of sucessional processes. Turrialba, 15: 40-42.

Carvalho, J.O.P.; Silva, J.N.M.; Lopes, J.C.A. 2004. Growth rate of a terra firme rain forest in Brazilian Amazonia over an eight-year period in response to logging. Acta Amazonica, 34: 209-217.

Cavaleri, M.O.; Oberbauer, S.F.; Ryan, M.G. 2006. Wood $\mathrm{CO}_{2}$ efflux in a primary tropical rain forest. Global Change Biology, 12: 1-17.

Finegan, B.; Camacho, M. 1999. Stand dynamics in a logged and silviculturally treated Costa Rican rain forest, 1988-1996. Forest Ecology and Management, 121: 177-189.

Finol, U.H. 1971. Nuevos parametros a considerarse en el análisis estrutural de las selvas vírgenes tropicales. Revista Forestal Venezolana, 18: 12. 29-42.

Francez, L.M.B; Carvalho, J.O.P; Jardim, F.C.S. 2007. Mudanças ocorridas na composição florística em decorrência da exploração florestal em uma área de floresta de Terra Firme na região de Paragominas, PA. Acta Amazonica, 37: 219-228.
Gonçalves, F.G.; Santos, J.R. 2008. Composição florística e estrutura de uma unidade de manejo florestal sustentável na Floresta Nacional do Tapajós, Pará. Acta Amazonica, 38: 229-244.

Hopkins, M.J.G. 2007. Modelling the known and unknown plant biodiversity of the Amazon basin. Journal of Biogeography, 34: 1400-1411.

Joker, D.; Salazar, R. 2000. Pentaclethra macroloba (Willd.) Kuntze. Danida Forest Seed Centre/CATIE. Seed Leaflet, n.35, set.. (http://www.dfsc.dk/pdf/Seedleaflets/Pentaclethra\%20macroloba_ int.pdf). Acesso em 10/05/2012.

Knight, D.H. 1975. A phytosociological analysis of species-rich tropical forest on Barro Colorado Island, Panamá. Ecological Monographs, 45: 259-284.

Kunz, S.H.; Ivanauskas, N.M.; Martins, S.V.; Silva, E.; Stefanello, D. 2008. Aspectos florísticos e fitossociológicos de um trecho de Floresta Estacional Perenifólia na Fazenda Trairão, Bacia do rio das Pacas, Querência-MT. Acta Amazonica, 38: 245-254.

Lima Filho, D.A.; Revilla, J.; Amaral, I.L.; Matos, F.D.A.; Coêlho, L.S.; Ramos, J.F.; Silva, G.B.; Guedes, J.O. 2004. Aspectos florísticos de 13 hectares da área de Cachoeira Porteira-PA. Acta Amazonica, 34: 415-423.

Lorenzi, H. 1992. Árvores Brasileiras - Manual de Identificação e Cultivo de Plantas Árboreas Nativas do Brasil. Vol. 01. Editora Plantarum. Nova Odessa, São Paulo. 352 pp.

Lorenzi, H. 2002. Árvores Brasileiras - Manual de Identificação e Cultivo de Plantas Árboreas Nativas do Brasil. Vol. 02. Editora Plantarum. Nova Odessa, São Paulo. 384 pp.

Magurran, A.E. 1988. Ecological diversity and its measurement. Princeton University Press, New Jersey, USA. 192 pp.

Malheiros, A.F.; Higuchi, N.; Santos, J. 2009. Análise estrutural da floresta tropical úmida do Município de Alta Floresta, Mato Grosso, Brasil. Acta Amazonica, 39: 539-548.

Mobot, 2011. Missouri Botanical Garden. W3 Tropicos, (http:// mobot.mobot.org/W3T/search/vast.html). Acesso em 07/07/2011.

Mori, A.S.; Boom, B. 1983. Ecological importance of Myrtaceae in an eastern Brazilian wet forest. Biotropica, 15: 68-70.

Müller-Dombois, D.; Ellemberg, H. 1974. Aims and methods for vegetation ecology. John Wiley \& Sons, New York, USA. 547 pp.

Oliveira, L.C; Valentim, N.W; Figueiredo, E.O; Franke, I.L. 2003. Impactos da exploração seletiva de madeira em áreas em processo de fragmentação florestal na Amazônia Ocidental. Cerne, 9: 213-220.

Oliveira, A.N.; Amaral, I.L. 2004. Florística e fitossociologia de uma floresta de vertente na Amazônia Central, Amazonas, Brasil. Acta Amazonica, 34: 21-34.

Oliveira, A.N.; Amaral, I.L.; Ramos, M.B.P.; Nobre, A.D.; Couto, L.B.; Sahdo, R.M. 2008. Composiçáo e diversidade florísticoestrutural de um hectare de floresta densa de terra firme na Amazônia Central, Amazonas, Brasil. Acta Amazonica, 38: 627-642. 
Parrotta, I.A.; Francis, I.K.; AJmeida, R.R. 1995. Trees of the Tapajós - A Photographic Field Guide. United States Department of Agriculture (USDA), Forest Service, International Institute of Tropical Forestry, Río Piedras, PR- USA. 370 pp.

Prance, G.T.; Rodrigues, W.A.; Silva, M.F. 1976. Inventário florestal de um hectare de mata de terra firme, $\mathrm{km} 30$ da estrada ManausItacoatiara. Acta Amazonica, 6: 9-35.

Programa Calha Norte, 2010. Ministério da Defesa. Plano de Desenvolvimento Local Integrado e Sustentável do Município de Caracaraí, Estado de Roraima (www.defesa.gov.br/index. php/programas-e-projetos/programa-calha-norte). Acesso em $18 / 07 / 2010$.

Rolim, S.G; Nascimento, H.E.M. 1997. Análise da riqueza, diversidade e relaçáo espécie-abundância de uma comunidade arbórea tropical em diferentes intensidades amostrais. Scientia Forestalis, 52: 7-16.

Santos, J.H.S; Ferreira, R.L.C; Silva, J.A.A; Souza, A.L.; Santos, E.S; Meunier, I.M.J. 2004. Distinçấo de grupos ecológicos de espécies florestais por meio de técnicas multivariadas. Revista Árvore, 28: 387-396.

Santos, G.C.; Jardim, M.A.G. 2006. Florística e estrutura do estrato arbóreo de uma floresta de várzea no Município de Santa Bárbara do Pará, Estado do Pará, Brasil. Acta Amazonica, 36: 437-446.

Schilling, A.C.; Batista, J.L.F. 2008. Curva de acumulação de espécies e suficiência amostral em florestas tropicais. Revista Brasileira de Botânica, 31: 179-187.
Silva, U.S.C. 2003. Fitossociologia do componente arbóreo e não arbóreo de uma Floresta Tropical em Cantá - RR. Dissertaçáo de Mestrado, Universidade Federal Rural da Amazônia, Belém, Pará. 63 pp.

Silva, J.N.M.; Lopes, J.C.A.; Oliveira, L.C.; Silva, S.M.A.; Carvalho, J.O.P; Costa, D.H.M.; Melo, M.S.; Tavares, M.J.M. 2005. Diretrizes para a instalação e medição de parcelas permanentes em florestas naturais da Amazônia Brasileira. Embrapa Amazônia Oriental, Belém, Pará, 36 pp.

Silva, K.E.; Matos, F.D.A.; Ferreira, M.M. 2008. Composição florística e fitossociologia de espécies arbóreas do Parque Fenológico da Embrapa Amazônia Ocidental. Acta Amazonica, 38: 213-222.

Souza, D.R.; Souza, A.L.; Gama, J.R.V.; Leite, H.G. 2003. Emprego de análise multivariada para estratificação vertical de florestas ineqüiâneas. Revista Árvore, 27: 59-63.

Souza, D.R.; Souza, A.L.; Leite, H.G.; Yared, J.A.G. 2006. Análise estrutural em floresta Ombrófila Densa de terra firme não explorada, Amazônia Oriental. Revista Árvore, 30: 75-87.

Vale Verde, 2012. Madeireira Vale Verde Ltda., (www.madeireiravale-verde.com). Acesso em 07/02/2012.

Yared, J.A.G.; Couto, L.; Leite, H.G. 1998. Composição Florística de Florestas Secundária e Primária, sob efeito de diferentes Sistemas Silviculturais, na Amazônia Oriental. Revista Árvore, Viçosa, 22: 463-474.

Recebido em: 21/03/2012

Aceito em: 06/10/2012 
